\title{
Surgical Treatment of Iatrogenic Low Variety Anal Stenosis with Diamond Flap Anoplasty - A Prospective Study
}

\author{
Islam MR ${ }^{1}, \mathrm{Ahmad} \mathrm{S}^{2}, \mathrm{Ahmed} \mathrm{T}^{3}$, Islam MA ${ }^{4}$, Hasan ASMFU ${ }^{5}$
}

Conflict of Interest: None

Received: 06.03.2020

Accepted: 15.06 .2020

www.banglajol.info/index.php/JSSMC
Key Words:

Anal stenosis, Diamond flap, Anoplasty.

\begin{abstract}
Background: Anal stenosis results from loss of anoderm with subsequent fibrosis and scarring of underlying tissue. The condition represents a technical challenge in terms of surgical management. It is a serious complication of anorectal surgery, most commonly seen after surgical haemorrhoidectomy. However, stenosis can also occur after perianal circumferential burn due to application of herbal medicine by village doctors.
\end{abstract}

Objective: This study was conducted to see the outcome of diamond-flap anoplasty for the treatment of moderate to severe anal stenosis.

Patients and interventions: Unilateral diamond flaps anoplasty was performed for moderate to severe anal stenosis. Final anal calibre of 25 to $26 \mathrm{~mm}$ was targeted. The demographic characteristics, causes of anal stenosis, number of previous surgeries, anal stenosis severity, postoperative complications and the time of return to work were recorded.

Results: From July 2012 to January 2017, 18 patients (12 males, 67\% and 6 female patients, $33 \%$ ) with a mean age of 34 years (range, 25-52) were treated. 15 of the patients had a history of previous haemorrhoidectomy and 3 had circumferential perianal chemical burn due to application of herbal medicine by village doctors. Five patients (28\%) had moderate anal stenosis and 13 (72\%) had severe anal stenosis. Preoperative, intraoperative, and 12-month postoperative anal calibration values were $9 \pm 3 \mathrm{~mm}$ (range, 5-15), $25 \pm 0.75 \mathrm{~mm}$ (range, 2426), and $25 \pm 1 \mathrm{~mm}$ (range, 23-27). The clinical success rate was $98.9 \%$. No severe postoperative complications were observed.

Conclusion: Diamond-flap anoplasty is a highly successful method for the treatment of anal stenosis caused by previous haemorrhoidectomy and perianal circumferential chemical burn by herbal medicine.

[J Shaheed Suhrawardy Med Coll 2020; 12(2): 67-71] DOI: https://doi.org/10.3329/jssmc.v12i2.56884

\section{Introduction}

Anal stenosis is an abnormal narrowing of the anal canal to a varying extent due to the loss of anoderm with resultant scarring and fibrosis. It is a rare but serious complication

1. Dr. Md. Rashidul Islam, Associate professor, Colorectal Surgery, Shaheed Suhrawardy Medical college, Dhaka.

2. Dr. Sami Ahmad, Associate Professor of Surgery, Shaheed Suhrawardy Medical College, Dhaka.

3. Dr. Tanvir Ahmed, Registrar (Surgery), Shaheed Suhrawardy Medical College and Hospital, Dhaka.

4. Dr. Md. Armanul Islam, Resident Surgeon (General), Shaheed Suhrawardy Medical College and Hospital, Dhaka.

5. Dr. A.S.M. Farhad U1 Hasan, Resident Surgeon (Casualty), Shaheed Suhrawardy Medical College and Hospital, Dhaka.

Address for Correspondence: Dr. Md. Rashidul Islam, Associate Professor, Colorectal surgery, Shaheed Suhrawardy medical college, Dhaka. Mobile: 01711279298, E-mail: rashidulbsmmu@gmail.com of anorectal surgery, most commonly seen after surgical haemorrhoidectomy specially after Whitehead haemorrhoidectomy. ${ }^{1,2}$ In our subcontinent anal stenosis is also seen to occur following healing of circumferential perianal burn due to application of some chemicals in the form of herbal medicine. It may be mild, moderate or severe depending on the severity of luminal narrowing. It may also be classified into high, mid, or low on the basis of its location at the level of anal canal. Diagnosis is usually straight forward. Careful history, local inspection, digital rectal examination, history of anal procedure especially haemorrhoidectomy is a strong evidence of anal stenosis. Patients usually report painful or difficult defecation, difficulty initiating evacuation and incomplete evacuation. Other symptoms include narrow stool, rectal bleeding and constipation. ${ }^{2}$ 
Treatment of anal stenosis will vary depending on the location, severity, and cause of the stenosis. Nonoperative treatment for patients with mild low stenosis should be instituted with stool softeners/bulking agents and anal dilatation. The condition represents a technical challenge in terms of surgical management. Surgical treatment is indicated for patients, with moderate to severe stenosis, with stenosis associated with ectropion and with mild stenosis who fail non-operative treatment. A variety of corrective surgical procedures are practiced worldwide. Every procedure has its pros and cons. An ideal procedure should have maximum satisfactory outcome with no or very minimum complications. ${ }^{1,2,3}$

\section{Objective}

The aim of this study was to investigate the results of diamond-flap anoplasty performed for the treatment of severe and low variety anal stenosis due to a previous haemorrhoidectomy \& chemical burn due to injudicious application of herbal medicine.

Patients and interventions: From July 2012 to January 2017, a total number of 18 consecutive patients with severe low type anal stenosis were treated with diamond flap anoplasty. Unilateral/ bilateral diamond flap anoplasty was done targeting a final anal calibre of 25 to $26 \mathrm{~mm}$. there were 12 males and 6 females ranging in age from 25 year to 52 year (mean age 34). In all patients, digital rectal examination was not possible, $87 \%$ complained of obstructive defecation, $79 \%$ of painful evacuation, and $23 \%$ of frequent episodes of bleeding during defecation. Inadvertent loss of anoderm at haemorrhoidectomy was the main cause for the stenosis. The time elapsed from anoderm loss to anoplasty varied from 4 months to 2 years. All operations were conducted under spinal anaesthesia in the lithotomy position. Mechanical bowel preparation was done. All patients received preoperative ceftriaxone1gm.and metronidazole infusion $500 \mathrm{mg}$ few hours before the procedure.

The procedure includes lateral internal sphincterotomy for all patients. Fibrotic stricture was incised up to dentate line. A diamond shape defect equivalent to diamond flap was made by excising the scar tissue of the stricture at lateral aspect of lower anal canal and anal verge. Incision was made to make the diamond flap adjacent and lateral to created defect. Incision was deepened through subcutaneous tissue. Flap was created with wide pedicle so that its blood supply was not jeopardized after mobilization. Good mobilization of skin and subcutaneous fat of the flap was performed to ensure suturing to the defect without tension. Mobilized flap was then sutured to the defect without tension with interrupted 3-0vicryl. Resultant lateral defect was closed. Final calibre of anal canal was tested by proctoscope to ensure that it could be easily passed through the anal canal.

\section{Postoperative care:}

Stool softeners were used for first few postoperative days to aid evacuation. Patient was discharged at the second POD. All patients were examined at 1,2 and 7days post operatively for any early complications and assessment of pain by using Visual Analogue Scale VAS (from 0-10). The outcomes of the procedure were evaluated after 3 and 6 months. No patients complained prolonged postoperative pain. No wound breakdown or flap loss or flap displacement occurred within seven days postoperatively. One patient developed transient gas incontinence resolved within 2 months of postoperatively. No patient developed wound infection. At 4 and 6 months postoperative follow up improved defecation, no pain at defecation and no per rectal bleeding were reported. All patients expressed overall satisfaction and improved quality of life.

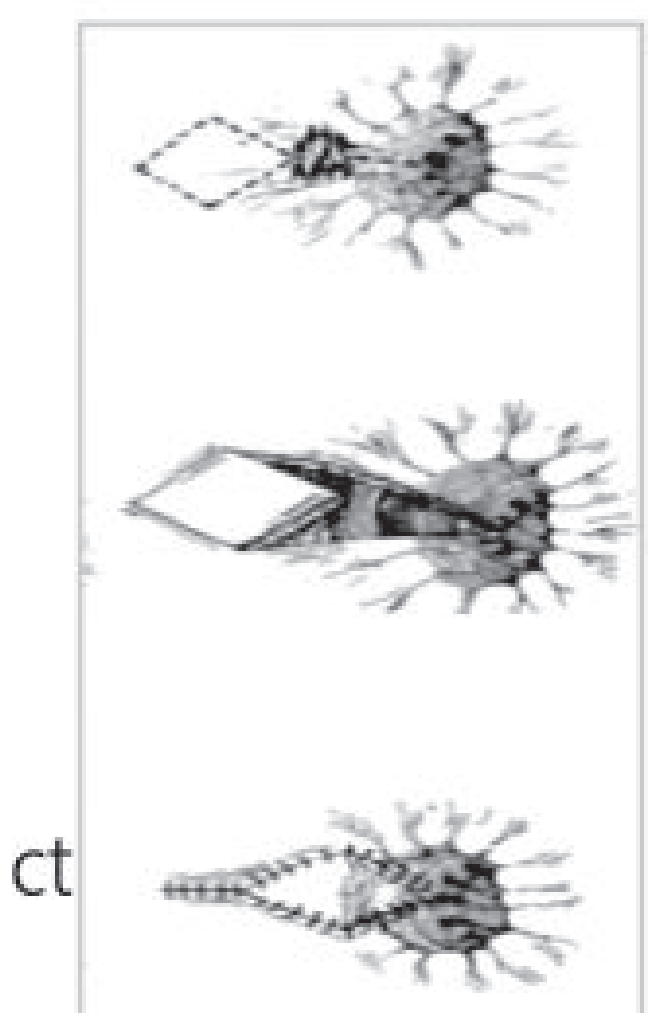

Fig-.-1: Diagrammatic representation of procedure for Diamond Flap. 


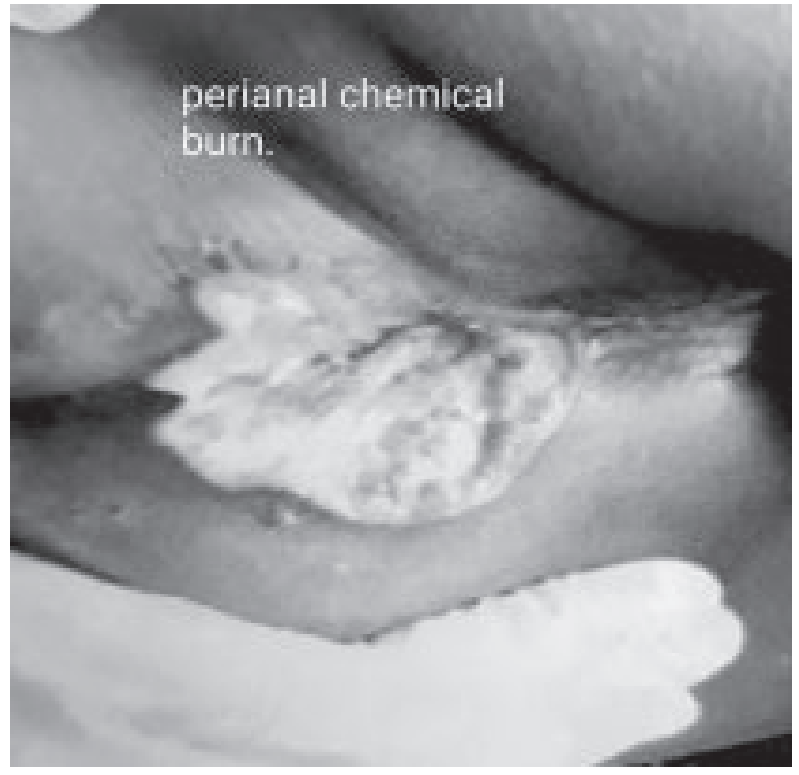

Fig.-2: Anal Ulcer with Anal Stenosis following Indigenous Medication.

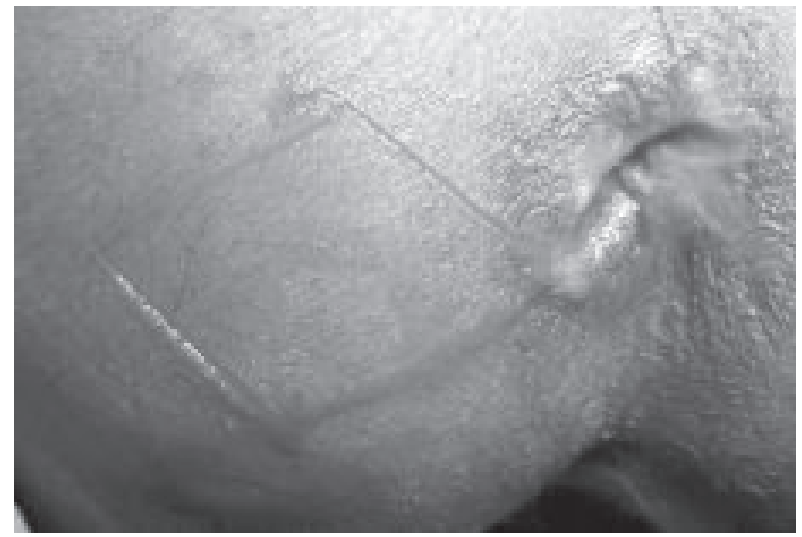

Fig.-3: Incision for Diamond Flap.

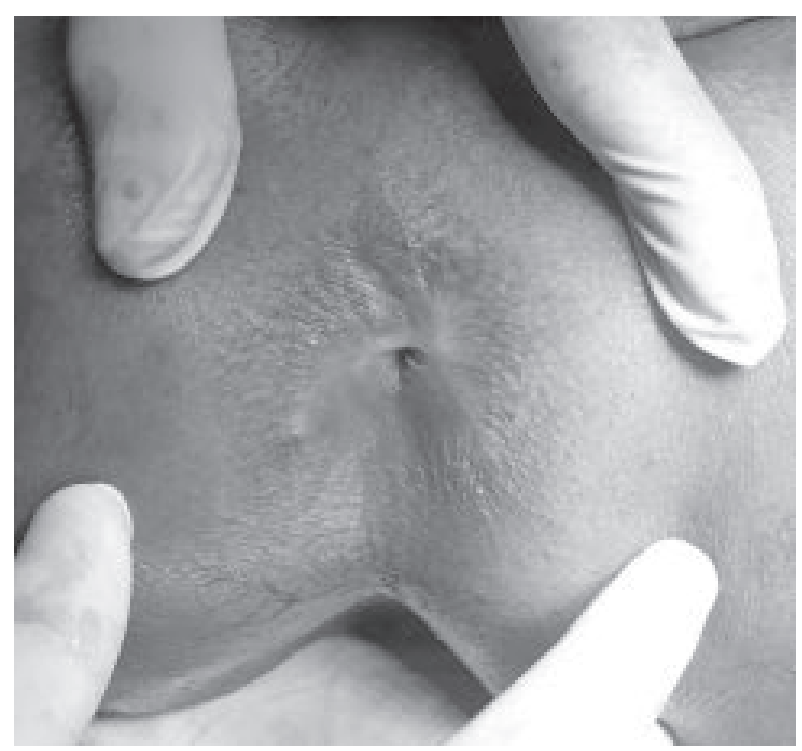

Fig.-4: Anal Stenosis following haemorrhoidectomy.

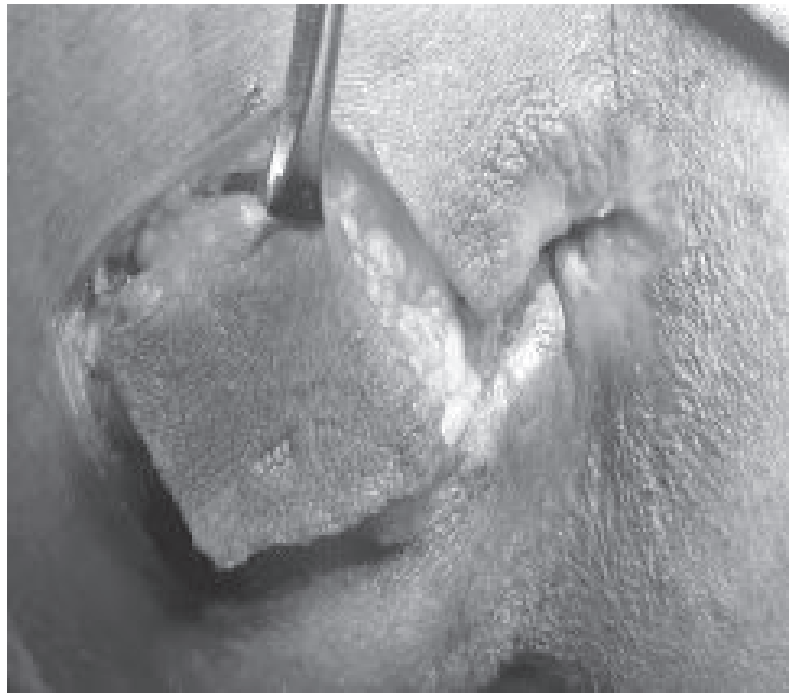

Fig.-5: Mobilisation of Diamond Flap.

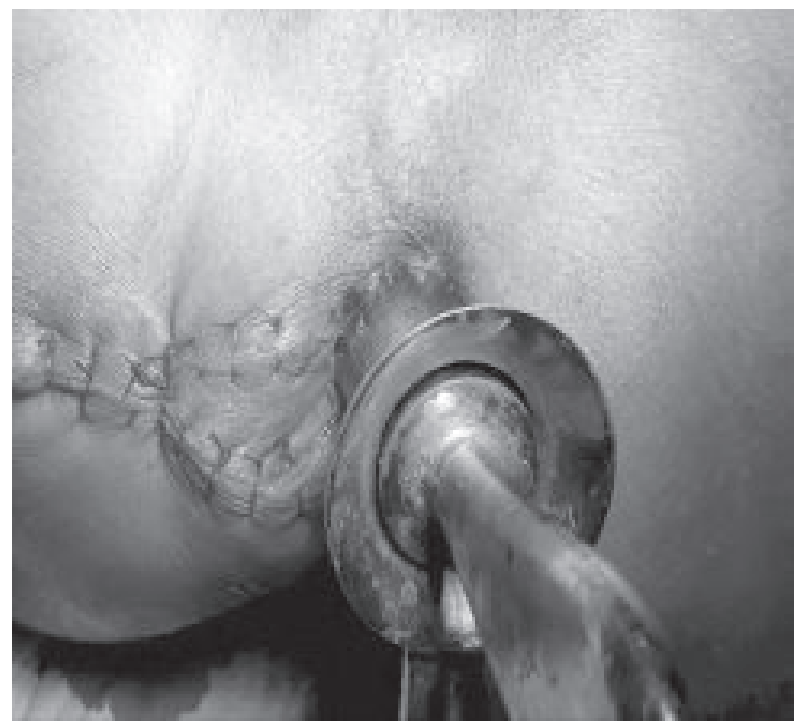

Fig-6: Adequate anal dilation after Diamond Flap Anoplasty.

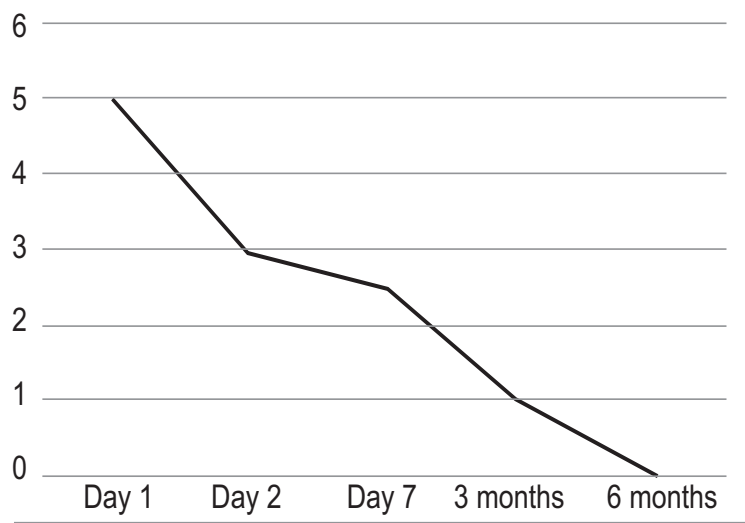

Fig.-7: Rate of decrease of pain and difficulty in defaecation following Dimond Flap Anoplasty. 


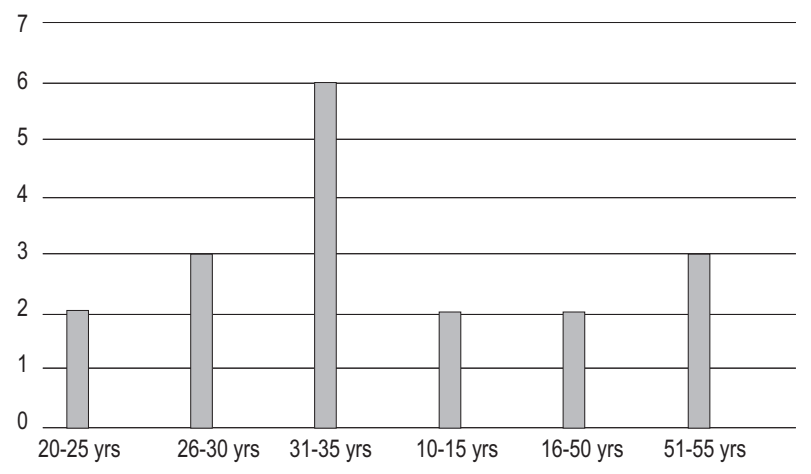

Fig.-8: Age distribution of patients presenting with anal stenosis.

\section{Discussion}

A lot of surgical techniques have been described for the management of moderate to severe anal stenosis. An ideal technique should be easily conducted with satisfactory results and low complication rate with short hospitalization. In this study we use diamond flap anoplasty to deliver more anoderm (skin) into the anal canal to fill the defect that results after cutting of fibrous scarring. Internal anal sphincterotomy was required to ease anal dilatation. ${ }^{13}$ Flap preparation is important for success of procedure, it is necessary to preserve much subcutaneous fat and wide mobilization to maintain flap viability and avoid suture line tension; also it is important to handle the tissue delicately to avoid damage to its blood supply. ${ }^{14}$ The use of bilateral flaps depends on the degree of anal dilatation after the completion of a unilateral flap. The use of lateral sphincterotomy gives more room for dilatation, decrease postoperative discomfort and reduce failure rate. ${ }^{15}$ The low complication rate and high patient's satisfaction were comparable to other studies and reflects the easiness and effectiveness of the technique, moreover diamond-shaped flap is designed so that it will cover the intra-anal portion of the defect. The flap is mobilized with minimal undermining to preserve the integrity of the subcutaneous vascular pedicle whereas in $\mathrm{V}-\mathrm{Y}$ anoplasty the tip of the $\mathrm{V}$ is subject to ischemic necrosis, and in Y-V flap the proximal part of the flap is very narrow and will not allow for a significant widening of the stricture above the dentate line, also the tip of the $\mathrm{V}$ within the anal canal is subject to ischemic necrosis from lack of mobilization, tension of the flap or loss of vascularization. In $\mathrm{C}$ and in $\mathrm{U}$ flaps the donor site left open. From above discussion diamond flap anoplasty seemed to be more effective measure than other available procedure for correction of severe low variety anal stenosis. G. Gallo et $\mathrm{al}^{10}$ in a study between January 2002 and September
2017, over 50 consecutive patients with moderate and severe anal stenosis performed rhomboid flap anoplasty. Complete improvement was found in $96 \%$ of patient. Merter Gülen et al ${ }^{11}$ conducted a study on 18 patients with severe anal stenosis. The clinical success rate was $88.9 \%$. No severe postoperative complications were observed. Maria et al. ${ }^{6}$ conducted a prospective study which compared Y-V anoplasty with diamond flap anoplasty in a median follow-up of 2 years. Complete resolution was reported for diamond flap anoplasty $(100 \%)$, whereas the healing rate for Y-V anoplasty was $90 \%$. Aitola et al. ${ }^{8}$ published a study in which 10 patients underwent Y-V anoplasty combined with internal sphincterotomy. The patients had a healing rate of $90 \%$ after 1 year of follow-up. Our study is consistent with the literature studies that evaluated this operation. Unilateral diamond-shaped flap anoplasty with partial lateral internal sphincterotomy succeeded in providing pain-free defecation and complete patient satisfaction in all of patients. We have no failure rate. In this surgical procedure recurrent symptoms can be corrected by operating the other side in the same manner. Post-operative complications can be easily controlled conservatively. The most critical issues of the procedure, that is, the flap preparation on a wide base and avoiding suturing over tension, must be adhered.

\section{Limitation}

The limitation of this study was the small sample size and inability of doing manometry preoperatively owing to stenosis and lack of instrumental support.

\section{Conclusion}

Diamond flap anoplasty is comparatively easy procedure with low complication rate and can be used for severe low variety anal stenosis resulted from a previous haemorrhoidectomy or circumferential perianal chemical burn due to injudicious application of herbal medicine.

\section{References}

1. Muayad J Lefta \& Qais K Baqir Diamond Flap Anoplaty For Severe Anal Stenosis. Bas J Surg, September, 19, 2013. 23-26.

2. Giuseppe Brisinda, Serafino Vanella, Federica Cadeddu, Gaia Marniga, Pasquale Mazzeo, Francesco Brandara, Giorgio Maria. Surgical Treatment of Anal stenosis

3. Casadesus D, Villasana LE, Diaz H, Chavez M, Sanchez IM, Martinez PP, Diaz A. Treatment of anal stenosis: a 5-year review. ANZ J Surg 2007; 77: 557-559

4. Gingold BS, Arvanitis M. Y-V anoplasty for treatment of anal stricture. Surg Gynecol Obstet1986; 162: 241242. Milsom JW, Mazier WP. Classification and management of postsurgical anal stenosis. Surg Gynecol Obstet 1986; 163: 60-64 
5. Milsom JW, Mazier WP. Classification and management of postsurgical anal stenosis. Surg Gynecol Obstet 1986; 163: 6064

6. Maria G, Brisinda G, Civello IM. Anoplasty for the treatment of anal stenosis. Am J Surg 1998; 175:158-160

7. Habr-Gama A, Sobrado CW, Araujo SE, Nahas SC, Birojm I, Nahas CS, Kiss DR. Surgical treatment of anal stenosis: assessment of 77 anoplasties. Clinics

8. Aitola PT, Hiltunen KM, Matikainen MJ. Y-V anoplasty combined with internal sphincterotomy for stenosis of the anal canal. Eur J Surg. 1997 Nov;163(11):839-

9. Khubchandani IT. Anal stenosis. Surg Clin North Am 1994; 74: $1353-1360$

10. G. Gallo E. Stratta A. Realis Luc G.Clerico M. Trompetto.
A tailored rhomboid mucocutaneous advancement flap to treat anal stenosis. Colorectal disease October 2020.Volume22, Issue10.Pages 1388-1395

11. Merter Gülen 1, Sezai Leventoðlu, Bahadir Ege, B Bülent Mente $^{\circ}$. Surgical Treatment of Anal Stenosis with Diamond Flap Anoplasty Performed in a Calibrated Fashion. Dis Colon Rectum. 2016 Mar;59(3):230-5. doi:

12. Shehata MS. Surgical management of iatrogenic anal stenosis. Egypt J Surg 2020;39:774-9

13. Thahzina Rahim, T.A.Vasu. Post Haemorrhoidectomy anal Stenosis - Correction with Diamond Flap Anoplasty. KERALA SURGICAL JOURNAL January 2020 | Vol 26 | No.1

14. Oh C, Zinberg J. Anoplasty for anal stricture. Dis Colon Rectum1982; 25: 809-810. 